\title{
Novel Technique for Enhancing the Strength of Friction Stir Spot Welds through Dynamic Welding Parameters
}

\author{
Ahmed Badwelan*(D), Ali M. Al-Samhan (D), Saqib Anwar (D) and Lotfi Hidri \\ Industrial Engineering Department, College of Engineering, King Saud University, Riyadh 11421, Saudi Arabia; \\ asamhan@ksu.edu.sa (A.M.A.-S.); Sanwar@ksu.edu.sa (S.A.); lhidri@ksu.edu.sa (L.H.) \\ * Correspondence: abadwelan@ksu.edu.sa; Tel.: +966-557067978
}

check for updates

Citation: Badwelan, A.; M.

Al-Samhan, A.; Anwar, S.; Hidri, L. Novel Technique for Enhancing the Strength of Friction Stir Spot Welds through Dynamic Welding Parameters. Metals 2021, 11, 280. https://doi.org/10.3390/met11020280

Academic Editors: Alessandro Morri, Lorella Ceschini and Stefania Toschi Received: 8 January 2021

Accepted: 30 January 2021

Published: 5 February 202

Publisher's Note: MDPI stays neutral with regard to jurisdictional claims in published maps and institutional affiliations.

Copyright: (c) 2021 by the authors. Licensee MDPI, Basel, Switzerland. This article is an open access article distributed under the terms and conditions of the Creative Commons Attribution (CC BY) license (https:// creativecommons.org/licenses/by/ $4.0 /)$.

\begin{abstract}
Presently, friction stir spot welding (FSSW) has become a common alternative for spot welding technologies. Over the years, researchers have implemented various methods for enhancing weld strength. However, the literature shows that the previously reported approaches have used static (constant) welding parameters set at the beginning of the welding stroke (i.e., the FSSW parameters were kept constant during the welding stroke). In contrast, in this study, an innovative technique is proposed for enhancing the weld strength for $\mathrm{Al} 1050$ material by adjusting the FSSW process parameters during the welding stroke. Two FSSW parameters, namely, feed rate and spindle speed (dynamic parameters), are used in this study with a stepwise variation function and are changed during the welding stroke. The results of this study show that the weld tensile strength is enhanced by $12-21 \%$ when using the proposed novel dynamic welding parameter technique. This is a significant increase in the weld strength compared to when static welding parameters are employed during the welding stroke.
\end{abstract}

Keywords: friction stir spot welding; weld strength enhancement; adjusting welding parameters; dynamic welding parameters; static welding parameters; Al 1050

\section{Introduction}

Recently, friction stir spot welding (FSSW) has become a popular alternative process for spot welding technologies [1]. FSSW has received attention from different industries, especially the automotive industry [2,3]. FSSW, which is a variant of friction stir welding (FSW), has many advantages in comparison to other welding techniques. For example, FSSW has lower investment and maintenance costs, as reported in [4], and lower consumption of the electricity and no coolants required, as mentioned in [5,6]. Moreover, the FSSW process can be performed on standard computer numerical control (CNC) milling machines, as compared to its competitor processes such as refill friction stir spot welding, where specialized equipment and tool are required to achieve the welds [7]. The FSSW is a solid-state welding process, where a rotating rigid tool is plunged inwards and outwards of the sheets with an overlapping technique at predefined rotation, plunge, and retracting speeds [8]. Additionally, the working environment in the case of the FSSW process is cleaner and operator friendly, because FSSW is a solid-state welding process without toxic fumes [4].

FSSW was first developed by Mazda Motor Corporation and Kawasaki Heavy Industry as an extension of FSW for joining aluminum alloys [9]. Friction stir spot welds have higher strength, better fatigue life, lower distortion, less residual stress, and better corrosion resistance as compared to the resistance spot welding as highlighted by [5]. Unlike FSW, in the case of the FSSW, there is no traverse movement after plunging a rotating tool into the strips being welded. The tool consists of a pin and shoulder. The pin is designed to disrupt the surface of the workpieces, shear, and move the material around it, producing deformational and frictional heat for the surface of the lap joint [10]. The tool shoulder produces most of the frictional heat on the surface and subsurface regions of the strips. The 
shoulder constrains the flow of plasticized material and produces a downward forging action [11].

To date, there have been many studies, reviews, and reports on FSSW, which usually focus on the process itself and tool parameters. For example, Su et al. [12] provided a simple thermomechanical analytical model for FSSW to study the effect of different pin-shaped tools with different shoulder and pin diameters on the welds' strength. The performance evaluation of the three different FSSW tools was compared in terms of the welds' fracture behavior, microstructure changes, microhardness distribution, and welding temperature. Their results confirmed that the three FSSW tools sufficiently met all design objectives, which indicates that the proposed design approach is a simple and feasible guideline for tool design. Similarly, Kim et al. [13] studied the effects of tool geometry and process parameters on the mechanical properties of dissimilar aluminum alloy welds. Two pintype tools with different shoulder profiles, concave and convex, were used in their study. Experimental results showed that the two shoulder profiles caused significant differences in the axial force and the mechanical properties of the joint.

Li et al. [14] studied the increase in the flow velocity at the lap interface of the halfthreaded pin tool and full-threaded pin tool. The found that the weld load failure of the half-threaded pin was greater than the full-threaded pin tool. The fracture morphologies showed a larger bonding width for the welds developed using the half-threaded pin. Paoder et al. [15] performed FSSW to study the effect of pin and shoulder geometry (cylindrical and triangular shapes) on the stir zone (SZ) characteristics and mechanical properties of welded samples. The outcome showed that changing the pin shape led to changes in the SZ area and mechanical properties of the joints. Abbas et al. [16] used the Taguchi method and found that the pin profile was the most influential parameter on the welds' tensile strength during FSSW of dissimilar aluminum alloys. Other parameters included in their study were tool rotational speed and plunging time. They reported that the contribution of the pin geometry was $61.5 \%$, the tool rotational speed was $20.1 \%$, and the plunging time was $18.4 \%$.

The literature review also shows that some studies focused on the enhancement of the FSSW welds' strength by changing the process parameters. For example, Chen et al. [17] studied the effects of the process parameters on the welds' strength of aluminum alloys. Design of experiments (DOEs) and analysis of variance (ANOVA) methods were used to check the effect of the tool plunge speeds and dwell time on the weld strength. The results showed that the dwell time affects the weld strength more significantly than the plunge speed. Paider et al. [18] performed FSSW to investigate the effects of the tool rotational speed and shoulder surface-penetration depth on the microstructure, temperature profiles, maximum tensile load, and failure modes. Their study concluded that the effect of the tool rotational speed on the maximum tensile load is similar to the effect of the shoulder penetration depth. Furthermore, it has been reported that increasing the tool rotational speed and shoulder penetration depth resulted in an increase in the tensile strength of the weld.

Patel et al. [19] investigated the effect of the FSSW tool rotational speed on the welds' strength and defects during the welding of dissimilar aluminum sheets (AA5052-H32 and AA6082-T6). They compared three different tool rotational speeds while keeping the other process parameters, such as tool design, tool tilt angle, plunge depth, and axial force constant. Their results showed defect-free samples for all three selected tool rotational speeds. Sekhar et al. [20] also studied and analyzed the effect of the tool rotational speed during the FSSW of AA5052-H38 aluminum sheets. The study found that the welds' tensile strength increases with a decrease in the rotational tool speed from 1300 to $900 \mathrm{rpm}$.

Pattanaik et al. [21] used the Grey-based Taguchi method to analyze the effect of the tool rotational speed, plunge rate, and dwell time on the mechanical strength of welds for Al 6061 Aluminum and AISI 316 steel. Three levels of the process parameters were selected. The Taguchi approach yields the optimal process parameter levels to obtain the maximum tensile strength of the welds. Piccini et al. [22] studied the effects of the 
tool penetration depth during welding and the relative position of the materials used in the superimposed dissimilar aluminum joints. Results showed that obtained joints were defect-free for all analyzed welding conditions. Rana et al. [23] performed FSSW on aluminum sandwich sheets at six tool rotational speeds to evaluate the optimum range. A comparative assessment was done showing that the optimum tool rotational speed for joining a sandwich sheet is $1800 \mathrm{rpm}$ and above.

Garg et al. [24] investigated the influences of different tool pin shapes along with rotational tool speeds and dwell time on the lap shear strength of a friction stir spot welded AA6061 alloy. Through an experimental design, the study's results indicated that the shear strength was significantly influenced by tool rotational speed followed by the pin shape and dwell time. Shahani and Farrrahi [25] studied the effect of stirring time. The effect of five different stirring times of friction stir spot welding on the lap-shear specimens of an Al 6061-T6 alloy was analyzed. They found that the microhardness is higher in the weld-region between the keyhole and shoulder.

It can be seen from the reviewed literature that researchers have employed several methods to enhance the weld strength. Most researchers have focused on investigating the process parameters, such as tool rotational speed, plunge rate, and retract rate, to improve the weld strength [17-20]. Some studies have attempted to achieve a higher weld strength by investigating different tool geometries [24]. However, other researchers have used distinguished approaches to enhance the weld strength. For example, a study reported in [26], attempted to improve the shear-lap tensile strength of an A1-Cu FSSW joint by introducing a $\mathrm{Zn}$ interlayer between the aluminum and copper sheets. The study concluded that regardless of the thickness, the $\mathrm{Zn}$ interlayer significantly improves the shear-lap tensile strength and the fracture energy of the welds.

In all the reviewed studies, the researchers used static welding parameters (SWP); that is, the FSSW parameters were set at the beginning of the welding stroke and remained fixed throughout the stroke. In this study, a novel technique has been proposed for enhancing the welds' strength by using dynamic welding parameters (DWP). The FSSW parameters, such as the spindle speed and the tool feed rate change during the welding stroke. Significant improvement in the tensile strength is observed when the dynamic welding parameters are used in the FSSW process as compared to when static welding parameters are employed.

\section{Material and Research Methodology}

The welded material properties, tool geometry and material, and welding parameters are vital in obtaining a sound FSSW process. Typically, FSSW welding parameters are constant during the welding stroke (i.e., static welding parameters (SWP)). Hence, to reach the maximum strength of the weld, it is essential to optimize these welding parameters for a given material and FSSW tool. Generally, the spindle speed (SS), tool feed rate (FR), and plunging depth (PD) are the main process parameters. A pin-type tool is used in the current research (Figure 1) as it is reported to give better results than pinless tools, as mentioned in studies [27-32].

The experiments are conducted in two phases. The first phase only used the static (fixed) FSSW parameters. In this phase, the welding parameters remained constant during the welding process. In the second phase, the welding parameters, including the FR and SS, were changed during the welding stroke, which is later termed as employing dynamic welding parameters $(D W P)$. In the DWP technique, the value of a welding process parameter $F R$ or $S S$ was increased or decreased during the welding stroke as compared to their initial value. For example, if $S S$ is the selected dynamic welding parameter, the process can start with $1000 \mathrm{rev} / \mathrm{min}$, FR $5 \mathrm{~mm}$, and $2.7 \mathrm{~mm}$ plunging depth. When the tool reached a $2.2 \mathrm{~mm}$ depth, $S S$ changed to $1500 \mathrm{rev} / \mathrm{min}$, while the other parameters were kept constant during the whole process. This case is called the SS dynamic welding parameter with the dynamic welding parameter ratio $\left(R_{D W P}\right)$ of 1.5 . The changing of the $D W P$ parameters (FF and SS) is shown in Figure 2, where $D W P_{i}$ and $D W P_{f}$ represent the values of the dynamic parameters at the beginning and end of the welding stroke, 
respectively. It should be noticed that the value of the parameters was only changed when the tool reached a plunge depth of $2.2 \mathrm{~mm}$ (i.e., after the tool pin was completely immersed in the strips and the tool shoulder contacted the surface). This is because the contact area become maximum when the shoulder touched the top strip surface after the pin penetration was completed, and consequently maximum contact forces were generated in the weld zone.

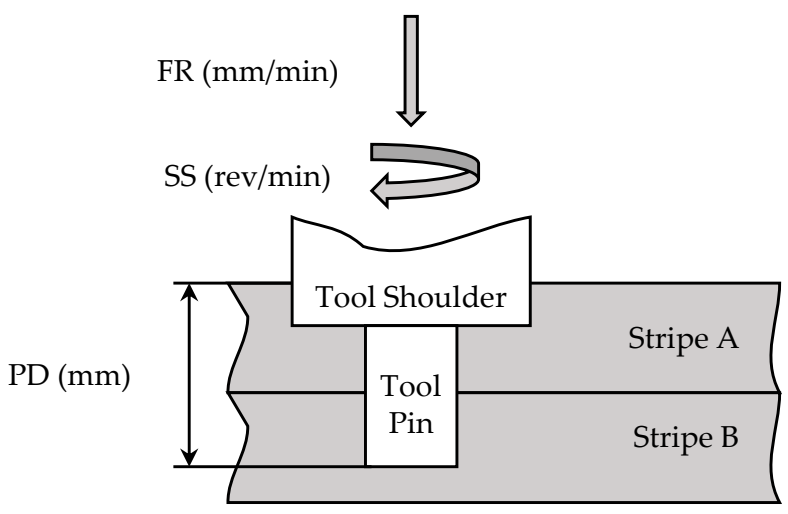

Figure 1. A schematic view of the friction stir spot welding (FSSW) tool type and process parameters.

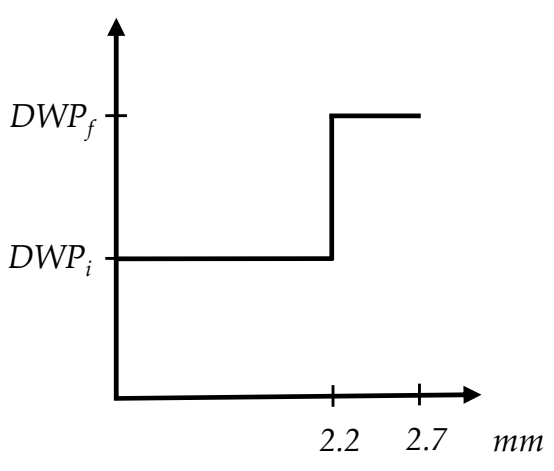

(a)

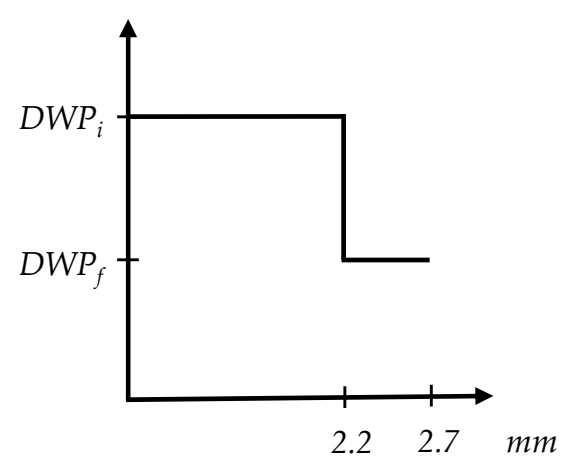

(b)

Figure 2. FSSW welding parameters as a stepwise variation function (a) dynamic welding parameter ratio $R_{D W P}>1$ (b) dynamic welding parameter ratio $R_{D W P}<1$.

\subsection{Research Framework}

The framework of this work is illustrated in Figure 3, which consists of two phases. The first phase is shown in the blue color and the second phase in the pink color. In the first phase, the initial step is running the FSSW experiments according to the full factorial DOE with static welding parameters $(S S, F R$, and $P D)$. Then, an optimizer tool via the individual desirability function is used to analyze the parameter combinations and their welds' strength (WS1, WS2, WSz). The desirability function evaluates the best setting of the input parameters to achieve an objective goal, more detail about the desirability function can be found in [33]. The output of the optimizer tool is the optimized combination of the static welding parameters (OSWP), which have the maximum weld strength. Minitab V16 software (V16, Minitab, United Kingdom) was used to analyze the experimental results and finding the optimum combination of the static welding parameters.

In the second phase, the FF and SS are employed as dynamic welding parameters, such that these parameters are changed when the tool reaches $2.2 \mathrm{~mm}$ plunge depth. In this phase, the optimized static welding parameters (ODWP) from the previous phase are considered as the initial value of these parameters and after the tool reaches the $2.2 \mathrm{~mm}$ plunge depth, then the values of DWP are either increased or decreased according to the selected $R_{D W P}$. The $R_{D W P}$ values selected in this study are $0.25,0.5,1$, and 1.5 . 


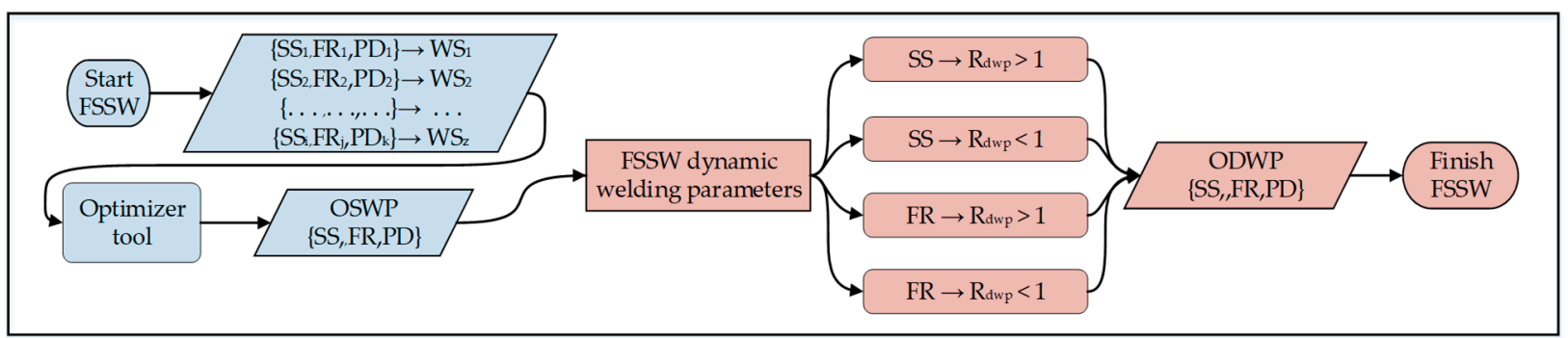

Figure 3. Research framework.

\subsection{Experimental Setup}

The experimental setup and the tensile testing setup for the welded strips are shown in Figure 4a-c, respectively. The experimental setup includes the computer numerical control (CNC) machine setup and welding fixture, FSSW tool, a load cell, and strips in lap-joint layout. The experiment was run on a German CNC vertical machining center model (DMG Mori-DMC 635 V Ecoline, EU, Germany), where a special fixture was developed and mounted on the machine with a load cell to measure the welding force and temperature sensors, as shown in Figure 4a,b. The holding tray of the fixture was assembled on top of the load cell. A round cylindrical temperature sensor was mounted at the center of the grip plate, such that the distance between the temperature sensor and the Al 1050 welded strips was $1.5 \mathrm{~mm}$ thick. The holding tray consisted of a grip plate assembly, welding strips, holding bracket, and holding screws. The main purpose of the developed welding fixture was to maintain the welding spot in the middle of the overlapping region of the Al 1050 strips. Data acquisition from the NI USB-6341 was used to collect the welding force and temperature during welding stroke.

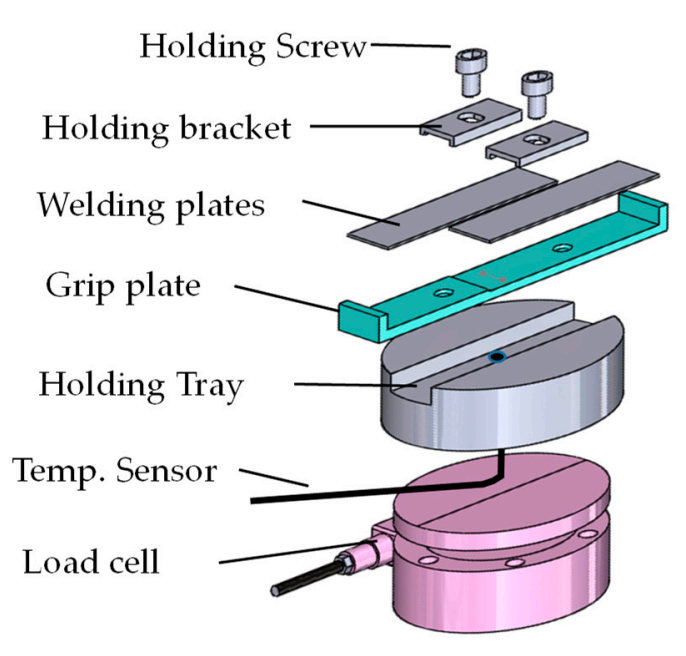

(a)

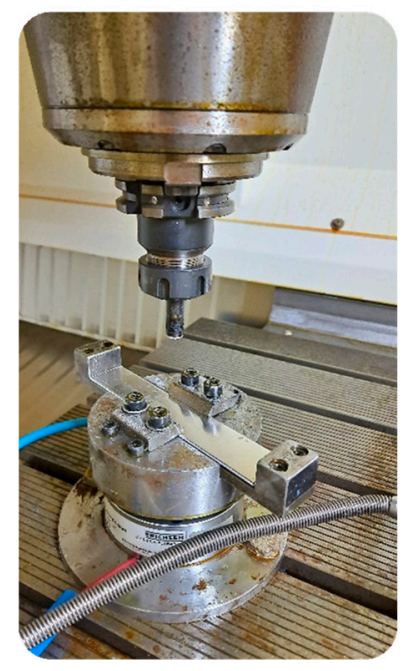

(b)

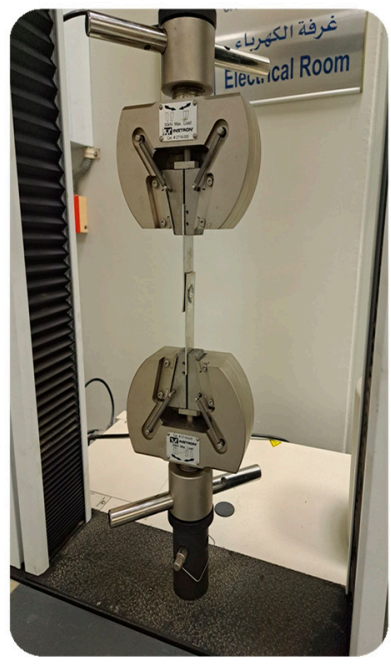

(c)

Figure 4. Experimental setup: (a) parts of the fixture; (b) machine setup; and (c) tensile test setup.

The material selected in this study is $\mathrm{Al} 1050$ due to its high electrical conductivity, corrosion resistance, non-toxic nature, and high ductility [34,35]. The $\mathrm{Al} 1050$ is commonly used in the automotive industry, food industry containers, and chemicals processing plant equipment. In many applications, $\mathrm{Al} 1050$ commonly receives spot welding processes [36,37]. The aim of the current study is to study the effect of the dynamic welding parameters on the weld strength of the $\mathrm{Al} 1050$ material. For each experiment, two overlapped Al 1050 strips with $100 \mathrm{~mm}$ length and $30 \mathrm{~mm}$ width are mounted on the fixture with a $40 \mathrm{~mm}$ overlap length. 
The strips have a thickness of $1.5 \mathrm{~mm}$, as shown in Figure 5b. Energy dispersive X-ray spectroscopy (EDS) was used to determine the chemical composition of the Al 1050 sample. The chemical composition (weight\%) and the mechanical properties of $\mathrm{Al} 1050$ strips is given in Table 1.

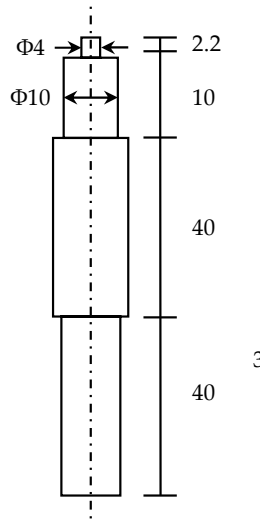

(a)

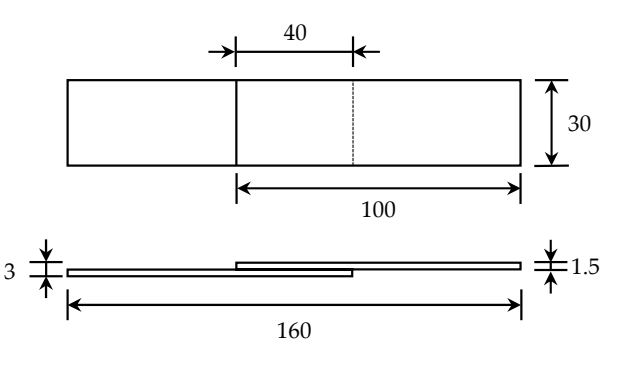

(b)

Figure 5. Illustration and dimensions of (a) the FSSW tool (H13 hot-work tool steel) and (b) Al 1050 strips (all dimensions are in $\mathrm{mm}$ ).

Table 1. Aluminum Alloy Al 1050 chemical composition and mechanical properties.

\begin{tabular}{cccc}
\hline \multicolumn{2}{c}{ Chemical Composition } & \multicolumn{2}{c}{ Mechanical Properties } \\
\hline Composition & Weight $\%$ & Property & Magnitude \\
\hline Aluminum $(\mathrm{Al})$ & 99.60 & Yield Strength $\sigma_{\mathrm{y}}(\mathrm{MPa})$ & 128 \\
Zirconium $(\mathrm{Zr})$ & 0.0015 & Ultimate Tensile Strength $\sigma_{\mathrm{UTS}}(\mathrm{MPa})$ & 117.5 \\
Strontium $(\mathrm{Sr})$ & 0.00013 & Elongation at Break A $(\mathrm{mm})$ & 8.45 \\
Vanadium $(\mathrm{V})$ & 0.0080 & Young Modulus E $(\mathrm{MPa})$ & 67,648 \\
Lithium $(\mathrm{Li})$ & 0.00010 & - & - \\
Others & 0.39027 & - & - \\
\hline
\end{tabular}

An FSSW pin tool (see Figure 5a) with a pin diameter of $4 \mathrm{~mm}, 2.2 \mathrm{~mm}$ height, and $10 \mathrm{~mm}$ flat shoulder diameter was manufactured with $\mathrm{H} 13$ tool steel to perform the welding process. A heat-treatment was used to harden the tool by heating it for $40 \mathrm{~min}$ at $1010^{\circ} \mathrm{C}$ followed by immersion in the oil.

The weld strength test was conducted by using an Instron ${ }^{\circledR} 3300$ mechanical testing system (see Figure 4c, Instron, MA, USA) with a tension rate of $5 \mathrm{~mm} / \mathrm{min}$. Vickers microhardness tests were performed in a DuraScan 10 computer (Struers A/S, Ballerup, Denmark). A load of $100 \mathrm{~g}$ was applied for $15 \mathrm{~s}$ with a spacing between the adjacent indents as per the ISO 6507-1:2018 standard. The same ISO standard was used for the microhardness measurements in references [38,39]. Microhardness measurements at each position were repeated three times for the selected FSSW specimens: Horizontally along the seam line of the welded specimen and vertically from the tool pin region (bottom to the top of the welded plates).

\subsection{Parametric Study}

Based on the full factorial design, it is observed from Table 2 that 90 experimental runs were required to cover the selected welding parameter levels $(6 \times 5 \times 3=90$ tests $)$.

A parametric study is an efficient technique used to analyze the effects of different variables and interactions of measurable outputs. To determine the influence of the process parameters on the measurable outputs in the FSSW process, a DOE was planned. The process parameters were chosen as (1) feed rate, (2) spindle speed, and (3) plunging depth, 
all of which were expected to have a significant effect on the measurable outputs, as reported in [40-42].

Table 2. Welding parameter levels obtained for experiment parametric study.

\begin{tabular}{cc}
\hline Welding Parameter & Welding Parameter Levels \\
\hline Feed rate, FR $(\mathrm{mm} / \mathrm{min})$ & $5,10,15,20,25,30$ \\
Spindle speed, $S S(\mathrm{RPM})$ & $1000,1500,2000,2500,3000$ \\
Welding depth, $P D(\mathrm{~mm})$ & $2.3,2.5,2.7$ \\
\hline
\end{tabular}

The welding parameter levels, which were assigned in the experiment are shown in Table 2. The screening experiments led to these parameter ranges because any level below or above these given ranges did not result in sufficient weld's strength.

\section{Results and Discussion}

\subsection{Static Welding Parametric Study}

Figure 6 shows the effect of the welding parameters on the welds' tensile strength. The vertical axis shows the welds' tensile strength, while the horizontal axis shows the spindle speed (1000 to $3000 \mathrm{rpm}$ ) categorized by the feed rate. These results are illustrated for different levels of plunging depths ranging from 2.3 to $2.7 \mathrm{~mm}$.

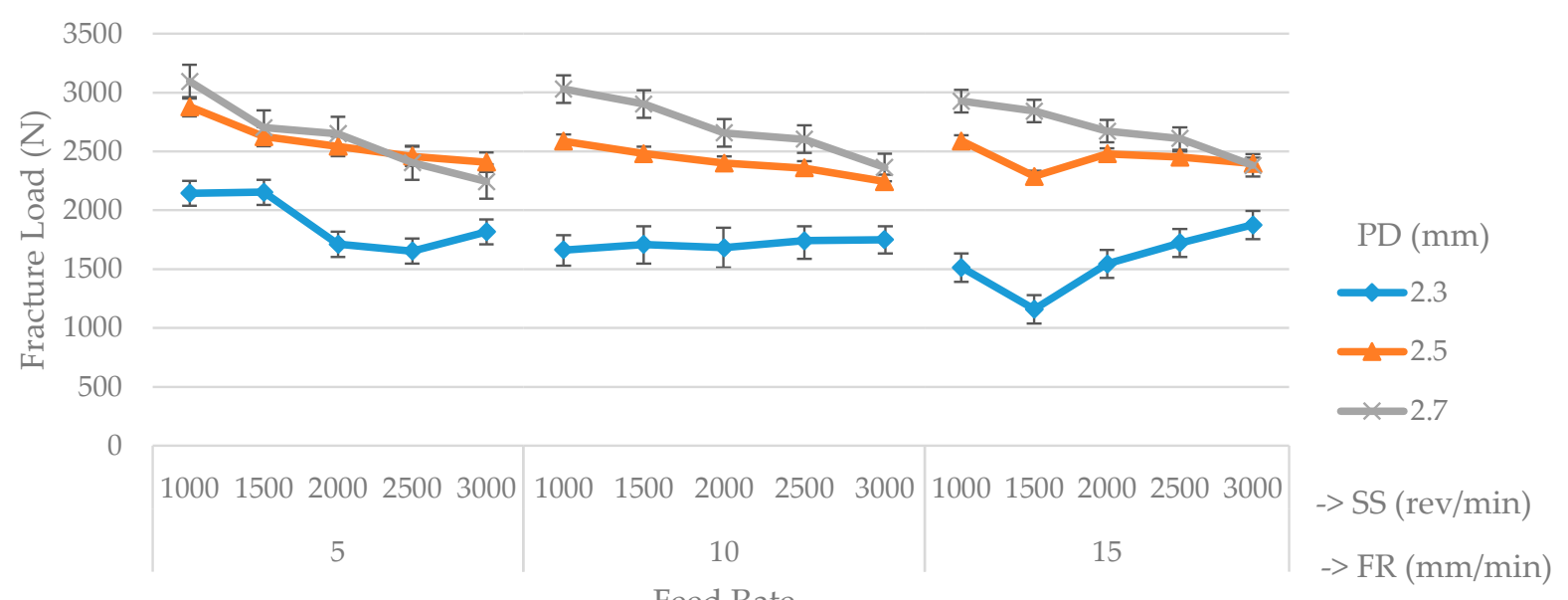

Feed Rate

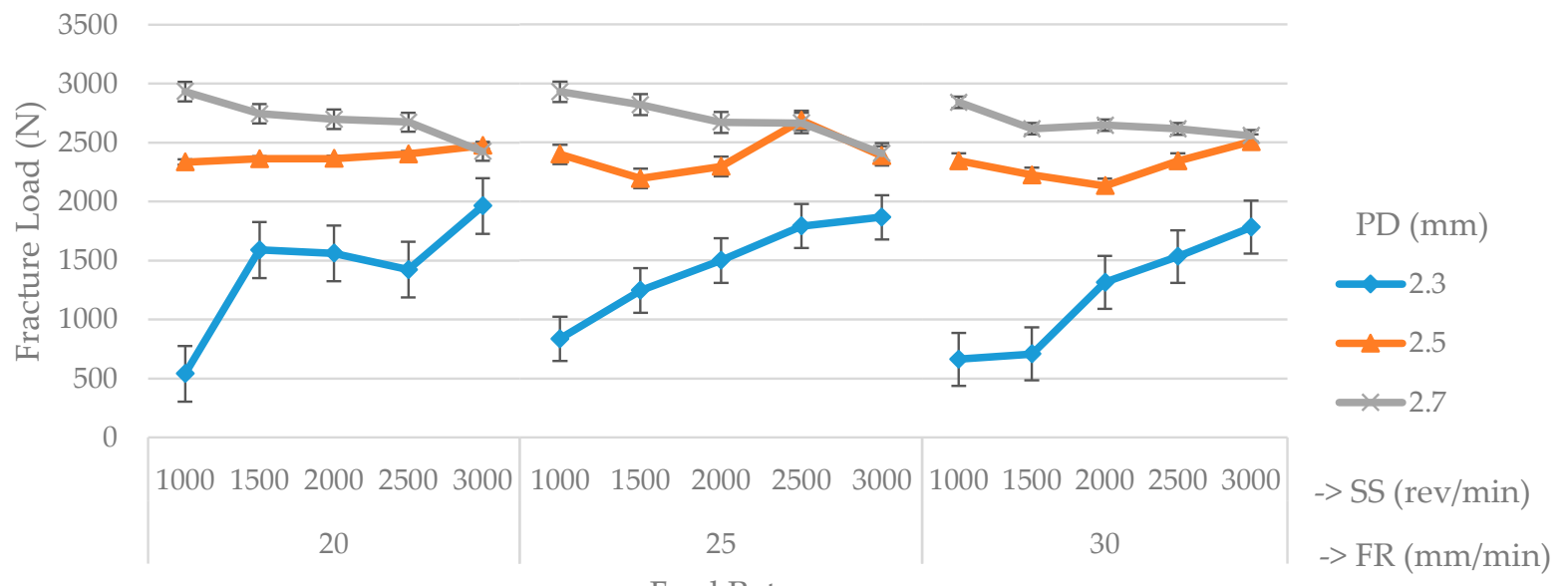

Feed Rate

Figure 6. Welding parameter effect on tensile strength of the welded joint. The error bars show the maximum and the minimum value of the measurements. 
Figure 6 shows that the welds' strength increases when the spindle speed decreases for the feed rate from $5-10 \mathrm{~mm} / \mathrm{min}$, and the highest tensile strength of the weld was obtained for a low spindle speed of $1000 \mathrm{rpm}$. Furthermore, the welds' strength increases with a decrease in the feed rate from 10 to $5(\mathrm{~mm} / \mathrm{min})$. However, the welds' strength values almost converged to low values for a spindle speed from 2000 to $3000 \mathrm{rpm}$ at all plunging depth ranges (see Figure 6). The results are supported by $[17,24,43]$ where they found the same behavior.

Moreover, the welds' strength increased with an increase in the plunging depth $(P D)$ from 2.3 to $2.7 \mathrm{~mm}$, and the reported welds' strength results are approximately within a narrow range between 2000 and $3000 \mathrm{~N}$ for 2.5 and $2.7 \mathrm{~mm}$ plunging depths. The highest strength of the weld was reported for a plunging depth of $2.7 \mathrm{~mm}$, which is illustrated in Figure 6.

Furthermore, it can be noticed that at lower spindle speeds (1000 and $1500 \mathrm{rev} / \mathrm{min})$, the effect of the $P D$ is dominant while it becomes ineffective at higher spindle speeds. This is because of material softening at higher spindle speeds which over little/negligible resistance to the increase in the $P D$.

From the results of the ninety experiments, the highest tensile strength of the weld was observed at $S S=1000 \mathrm{rev} / \mathrm{min}, F R=5 \mathrm{~mm} / \mathrm{min}$, and $P D=2.7 \mathrm{~mm}$ (Table 3). To further confirm that this is the optimum combination of the parameters, an individual desirability function was used. Desirability function also outputs the same combination of the FSSW parameters yielding the $3092.7 \mathrm{~N}$ as the highest fracture load of the weld, as shown in Table 3. Coincidently, the maximum fracture load predicted by the desirability function is the same as already available in the results of the 90 experiments shown in Figure 6. However, to be systematic, it is preferred to use the available tools such as desirability function to confirm the optimum combination of the parameters.

Table 3. Combination of the optimized static welding parameters.

\begin{tabular}{cccc}
\hline \multicolumn{2}{c}{ Minitab Optimized Welding Parameters } & \multirow{2}{*}{ Weld's Strength } \\
\cline { 1 - 2 } & $\boldsymbol{F R}$ & $\boldsymbol{P D}$ & \\
\hline $\mathbf{1 0 0 0} \mathrm{rev} / \mathrm{min}$ & $5 \mathrm{~mm} / \mathrm{min}$ & $2.7 \mathrm{~mm}$ & $3092.7 \mathrm{~N}$ \\
\hline
\end{tabular}

\subsection{Weld's Strength Enhancement Study Using DWP}

\subsubsection{Results of DWP}

In this study, the spindle speed and feed rate were considered as dynamic welding parameters. Different values of the dynamic welding parameter ratios $\left(R_{D W P}\right)$ from 0.25 to 1.5 were used, and the values of the DWP at the beginning and end of the welding stroke are given in Table 4 for the corresponding $R_{D W P}$ values.

Table 4. Tensile Strength Results for dynamic welding parameter (DWP).

\begin{tabular}{|c|c|c|c|c|}
\hline$R_{\text {DWP }}$ & DWP & Initial Parameters & End Parameters & Fracture Load \\
\hline 1 & NA & $S S=1000, F R=5, P D=2.7$ & $S S=1000, F R=5, P D=2.7$ & $3092.7 \mathrm{~N}$ \\
\hline \multirow{2}{*}{0.25} & SS DWP & $S S=1000, F R=5, P D=2.7$ & $S S=250, F R=5, P D=2.7$ & $3758.0 \mathrm{~N}$ \\
\hline & FF DWP & $S S=1000, \boldsymbol{F R}=5, P D=2.7$ & $S S=1000, \boldsymbol{F R}=1.25, P D=2.7$ & $3173.5 \mathrm{~N}$ \\
\hline \multirow{2}{*}{0.5} & SS DWP & $S S=1000, F R=5, P D=2.7$ & $S S=500, F R=5, P D=2.7$ & $3488 \mathrm{~N}$ \\
\hline & FF DWP & $S S=1000, \boldsymbol{F R}=5, P D=2.7$ & $S S=1000, \boldsymbol{F R}=2.5, P D=2.7$ & $3142.2 \mathrm{~N}$ \\
\hline \multirow{2}{*}{1.5} & SS DWP & $S S=1000, F R=5, P D=2.7$ & $S S=1500, F R=5, P D=2.7$ & $2996.4 \mathrm{~N}$ \\
\hline & FF DWP & $S S=1000, \boldsymbol{F R}=5, P D=2.7$ & $S S=1500, F R=7.5, P D=2.7$ & $2989.6 \mathrm{~N}$ \\
\hline
\end{tabular}

The bold letters represent the welding parameters being changed during the dynamic welding stroke. 
Figure 7 shows that the welds' strength was enhanced when a step variation of the SS was introduced. The welds' strength enhancement increased with a decrease in the $R_{D W P}$ from 1.5 to 0.25 . The same trend was reported for the step variation $F R$ results.

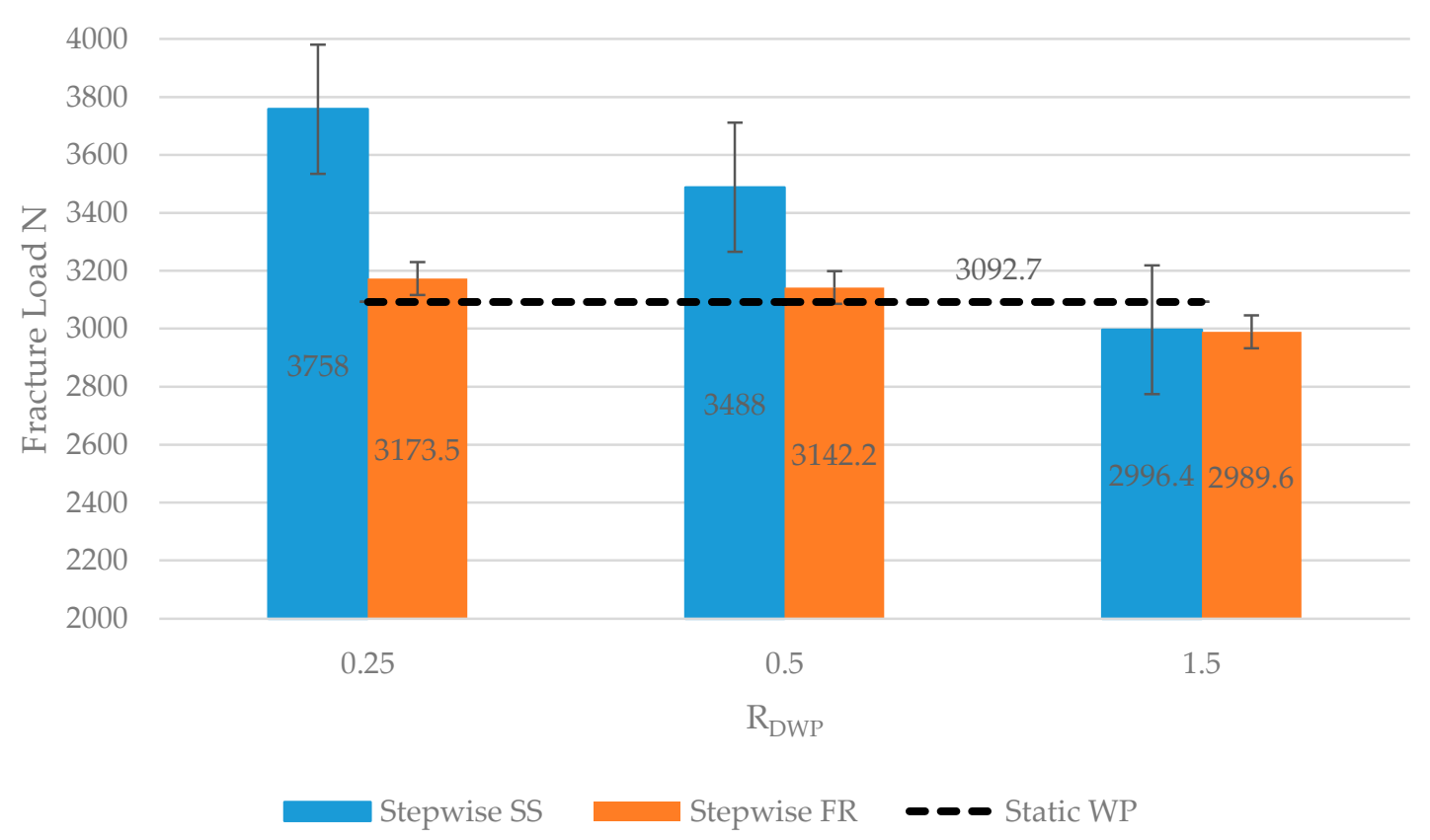

Figure 7. Comparison of the tensile strength results for DWP and static welding parameter (SWP).

From Figure 7, we can conclude that there is a significant improvement in weld's strength up to $21 \%$, when the spindle speed is considered as the dynamic welding parameters with $R_{D W P}=0.25$. Generally, the weld's strength was enhanced with a decrease in the dynamic welding ratio $\left(R_{D W P}\right)$.

The force and temperature signals recording during the welding strokes were further investigated to understand the underlying phenomena of why the weld's strength changes by using the dynamic welding parameters.

\subsubsection{Welding Force and Temperature Results}

According to Figure 8, the required time duration of the welding process is not the same for all experiments. This is due to the variability of the $F R$ (dynamic feed rate). In addition, this duration increases whenever the $R_{D W P}<1$. For the case of $R_{D W P}>1$, the reverse behavior is observed. In addition, due to the increase in cycle time in the case of $R_{D W P}<1$, the contact time of the tool increases, which causes an increase in temperature distribution due to the friction effect. This explains the reason for the temperature increase in the case of $R_{D W P}<1$, as shown in Figure 9. The increase in temperature reduces the solid welding state and decreased the welding force (see Figure 8). It should be noted that throughout the FSSW process, the material in the weld-zone remains in the solid-state (i.e., it does not melt like in other conventional welding approaches). However, thermal softening happens due to increase in the temperature because of friction. These results are in agreement with [44]. It can be observed that overall the welding forces are less in the case of the dynamic feed rate as compared to the welding forces in the case of when the $S S$ is used as a dynamic welding parameter for $R_{D W P}<1$, as shown in Figures 8 and 10. This is because, for $R_{D W P}>1$, the increase in the spindle speed from its initial value results in higher temperatures leading to a reduction in the solid-state weld (thermal softening), which subsequently reduced the welds' strength. 


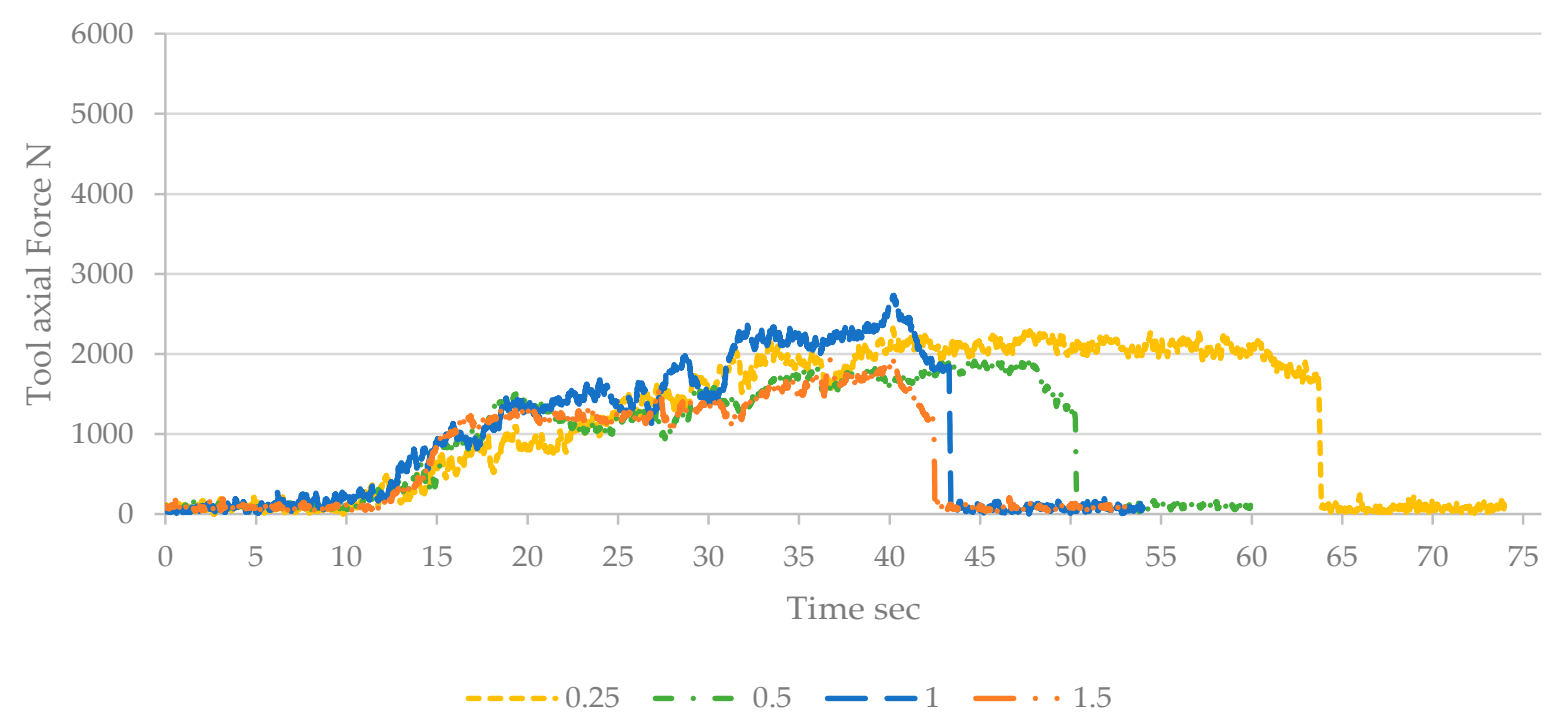

Figure 8. Effect of changing the feed rate during the weld stroke on welding force from $R_{D W P}=0.25$ to 1.5.

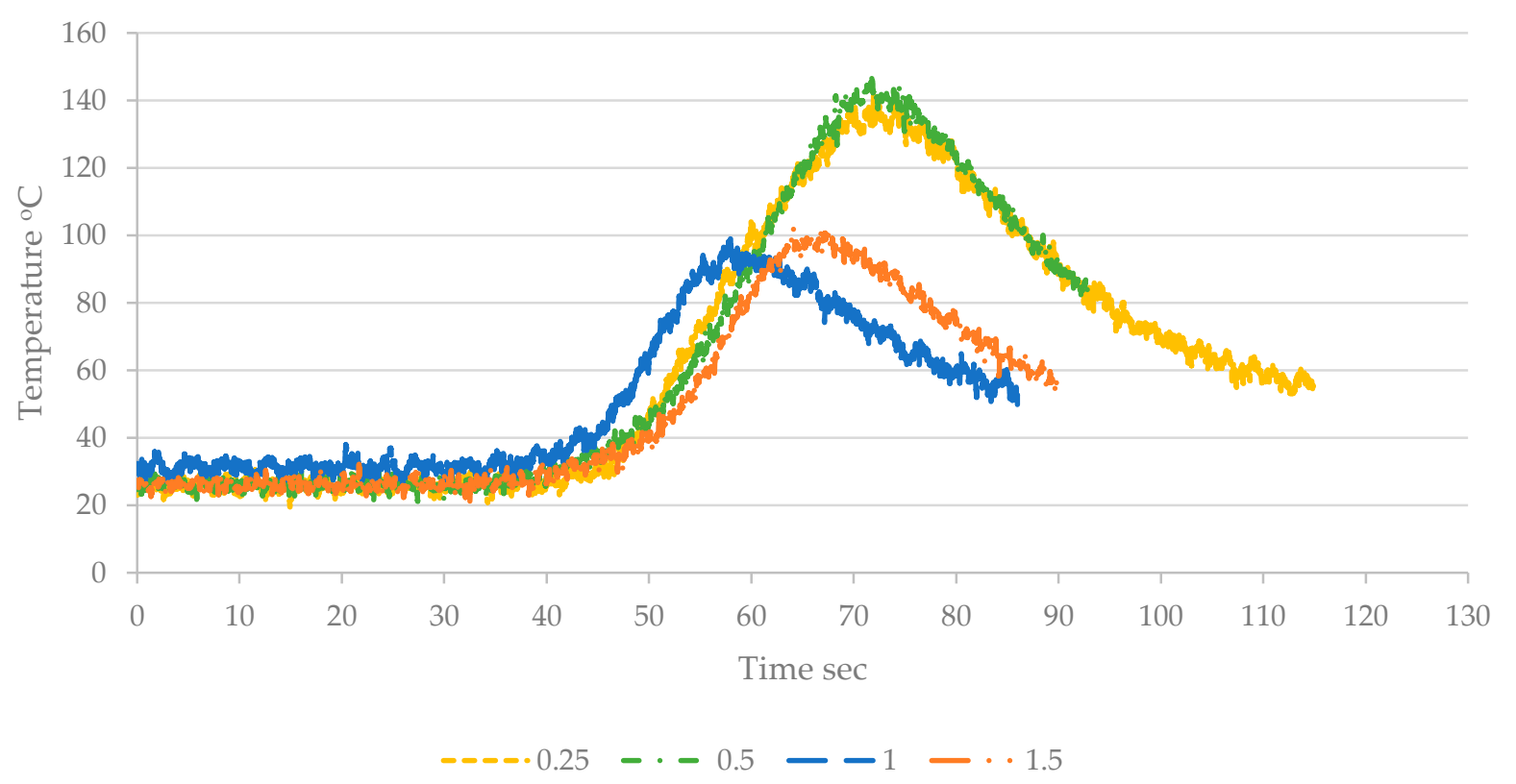

Figure 9. Effect of changing the feed rate during the weld stroke on temperature from $R_{D W P}=0.25$ to 1.5.

It should be noted that the temperature values in Figure 9 are lower because the temperature sensor is located away from the weld zone due to the limitations that it cannot be installed within the weld zone. Therefore, the temperature values are representatives of the actual temperature generated in the weld zone rather than the actual temperature values in the weld zone.

An overlap can be noticed in the temperature curves for the $R_{D W P}$ values of 0.25 and 0.5 as compared to when the $R_{D W P}$ value is over 1 . This is because of the following reasons: (i) The step difference is only 0.25 in the case of $R_{D W P} 0.25$ and 0.5 , whereas, in the preceding $R_{D W P} 1$ and 1.5, the difference is 0.5 (i.e., double). This results in the temperature distribution for $R_{D W P} 0.25$ and 0.5 remains nearly the same. (ii) Additionally, the cycle times for the 0.25 and 0.5 are significantly higher as compared to $R_{D W P} 1$ and 1.5. Therefore, more heat transfer occurred between the weld-zone and the thermocouple in the former case. 
Generally, when the spindle speed increases, the friction increases and leads to a rise in the peak welding temperature. This phenomenon has been discussed and reported in other studies such as [45-48]. In the current case, when the dynamic welding ratio is $R_{D W P}>1$, the spindle speed is increased from its initial value. This increase change results in a decrease in the solid welding state, as well as a decrease in the welding force (Figures 8 and 10). However, in the case of $R_{D W P}<1$ (e.g., $R_{D W P}=0.25$ ), the spindle speed is reduced at the end of the welding stroke from 1000 to $250 \mathrm{rpm}$, which decreases the welding temperature, as shown in Figure 11. Furthermore, the thermal softening is reduced and increase in the weld strength is observed from $3092.7 \mathrm{~N}$ for $R_{D W P}=1$ to $3758.0 \mathrm{~N}$ for $R_{D W P}=0.25$ (i.e., an increase of $21.5 \%$ ). Therefore, the spindle speed as a dynamic welding parameter with $R_{D W P}=0.25$ was sufficient to keep the stirring zone active and increase the welds' strength, as shown in Figure 7.

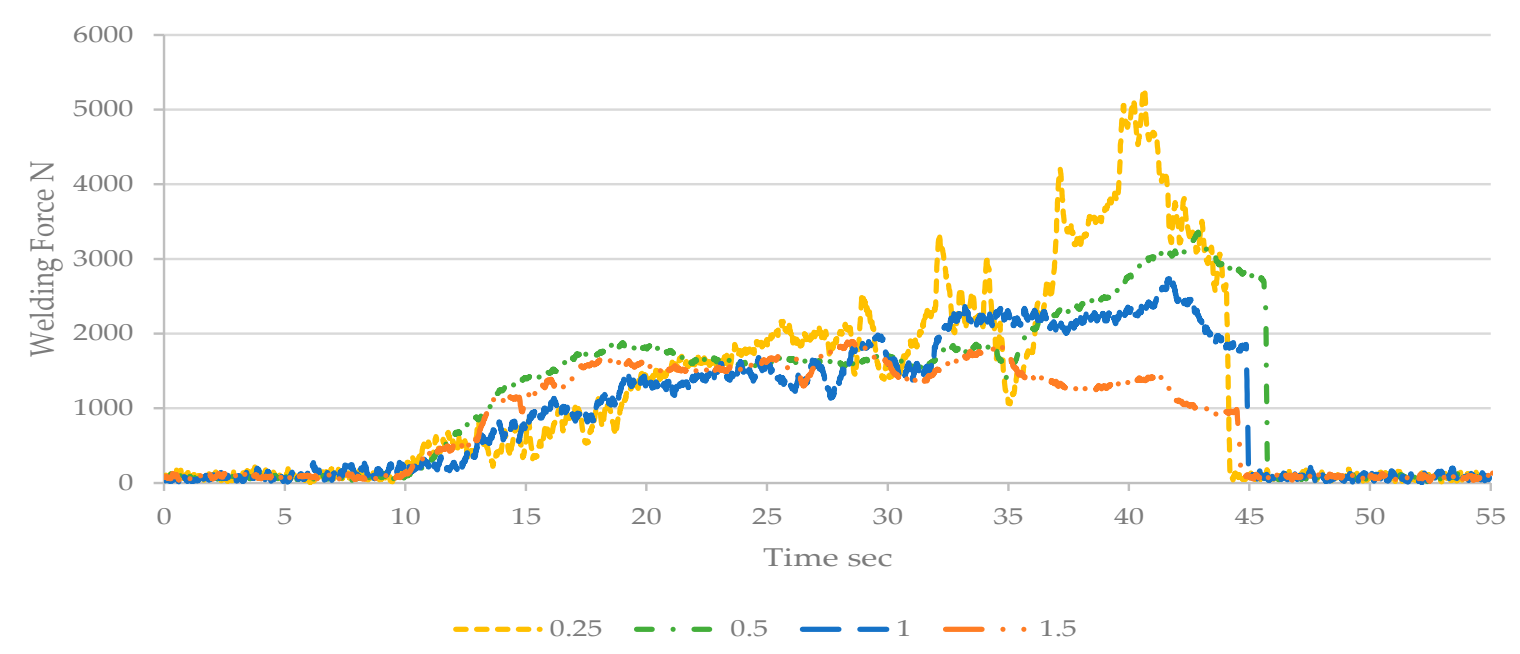

Figure 10. Effect of changing the spindle speed during the weld stroke on weld force from $R_{D W P}=0.25$ to 1.5 .

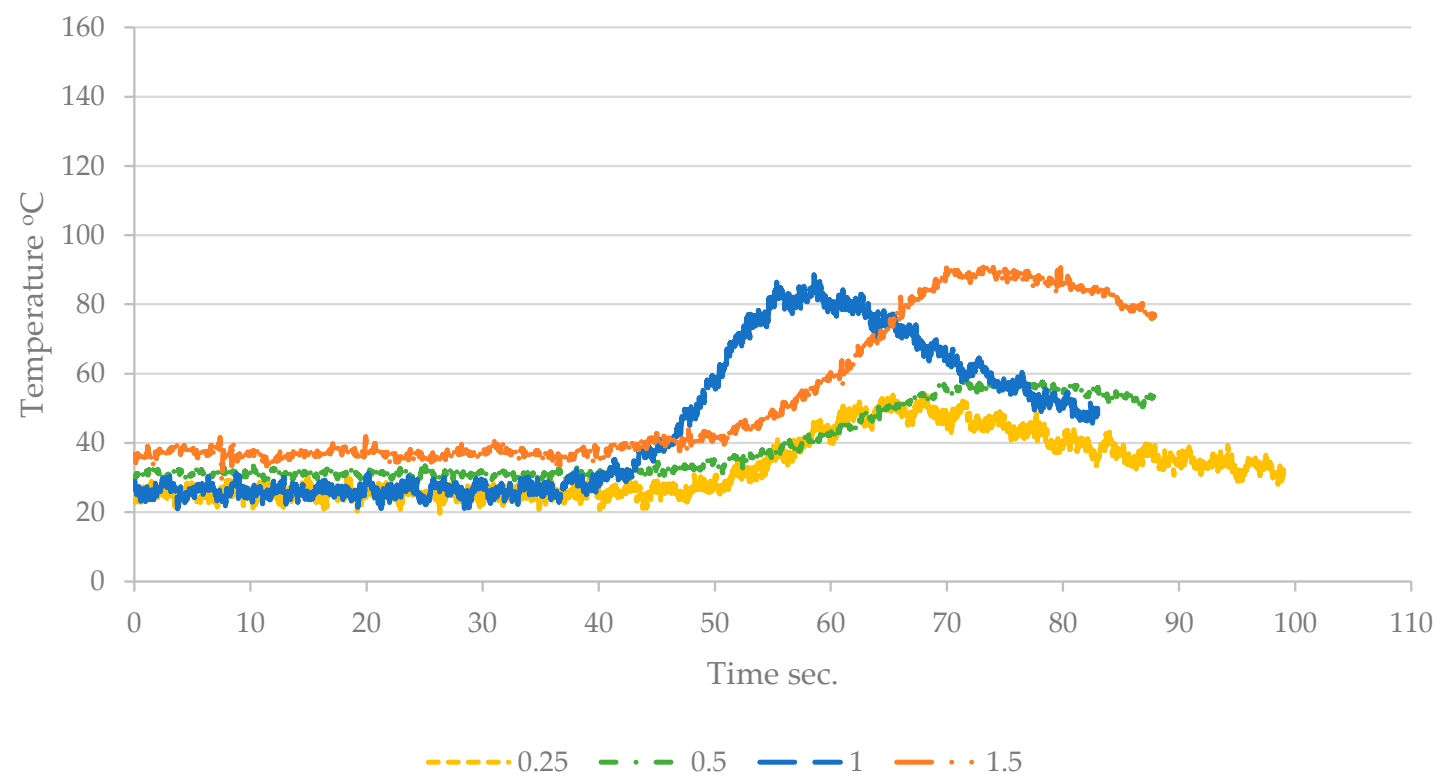

Figure 11. Effect of changing the spindle speed during the weld stroke on the temperature from $R_{D W P}=0.25$ to 1.5 .

It can be noticed that the cycle time changes significantly with $R_{D W P}$ variation in the case of the feed rate. At the same time, the cycle time remains almost fixed in the case of the spindle speed. This is because for a fixed stroke length $(5 \mathrm{~mm})$, the cycle time is the function of the feed rate, and is not affected by the spindle speed, as given in Equation (1). The small 
variation in the cycle time in the case of the spindle speed is due to the small burrs on the strip edges or the deformation in the edges of the strip from the prior blanking operation. This results in premature contact of the strips' edges with the force sensor as the welding tool approaches the lap joint. Regarding the effect of the $R_{D W P}$ in conjunction with the feed rate and spindle speed on the weld's strength, the effect of the $R_{D W P}$ is less dominant for feed rate, whereas it has a significant impact on weld's strength in the case of the spindle speed. For example, in the case of the spindle speed with $R_{D W P} 0.25$, we combined the scenario of high speed at the beginning of the cycle with the low speed at the end of the cycle. That is in the beginning of the cycle, the heating is produced in the stir zone by a high spindle speed of 1000 rpm. However, the remaining cycle (after $2.2 \mathrm{~mm}$ plunge depth, see Figure 2) is followed by the reduced spindle speed of $250 \mathrm{rpm}$, which leads to an increase in the bonding width due to the decrease in the temperature, and an increase in the solid-state welding, i.e., stirring zone remains active for a longer time [31-34]. It should be noticed that keeping high spindle speed for longer time would result in heat concentration and reduce the active stir zone $[47,48]$.

$$
\text { Cycle Time }=\frac{\text { Stroke Length }(\mathrm{mm})}{\text { Feed Rate }\left(\frac{\mathrm{mm}}{\mathrm{min}}\right)} .
$$

It can be observed that there are important differences in the peak temperatures in Figure 9, but there are no important differences in maximum forces, in Figure 8, for the same tests. This is because the variations in the temperatures are mainly due to the differences in the weld stroke time. For example, the welding stroke for dynamic feed rate at $R_{D W P}=0.25$ will take almost $46 \%$ more time leading to increase in the contact time and friction, which lead to more accumulation of heat (i.e., higher temperatures). Contrary to what was expected, the forces do not reduce for the same test because higher temperatures cause more accumulation of softened/semi-solid material around the tool, thus resisting its progression into the workpiece.

\subsubsection{Results of the Microhardness}

Figure 12 shows how the micro Vickers hardness (HV $100 \mathrm{gf} / 15 \mathrm{~s}$ ) measurements were taken from the sample. Two directions were selected to measure the microhardness, horizontal, and vertical directions. The vertical direction was selected near the tool pin surface ( $0.1 \mathrm{~mm}$ shift from the pin surface) along the bonding depth direction as shown in Figure $12 \mathrm{~b}$, and horizontal measurement locations were along the weld seam line as shown by the horizontal line in Figure $12 \mathrm{~b}$ along the bonding width direction.

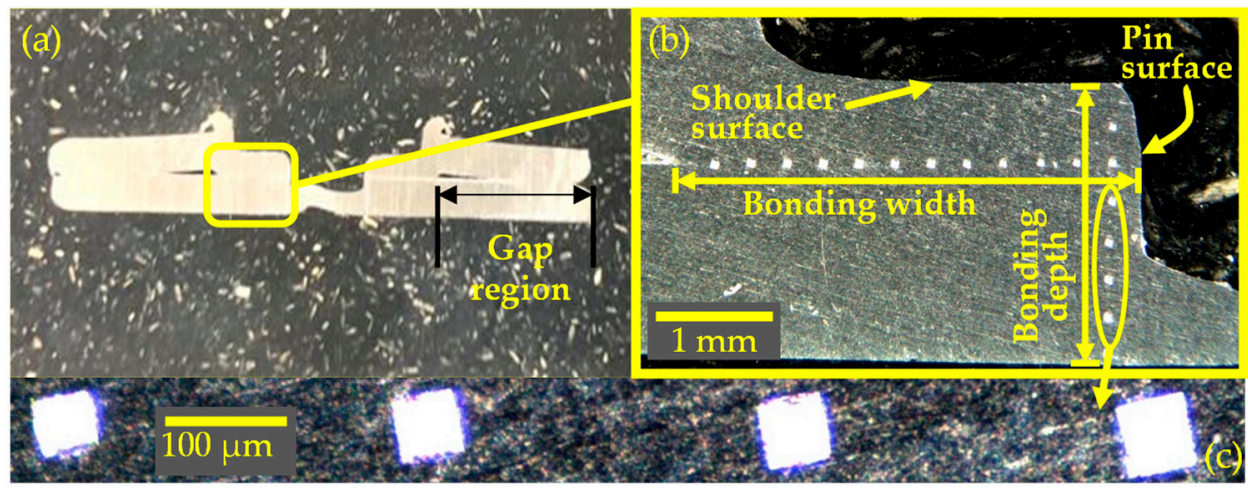

Figure 12. Microhardness measurements: (a) Cross-section of the weld showing the weld joint region and the region beyond the weld joint (gap region), (b) an example of the microhardness measurements along the bonding width and depth directions; (c) zoomed-in view of the microhardness indentations.

Figures 13 and 14 show the hardness of the welded specimens along the bonding width and depth directions, respectively. The microhardness results are presented for static welding parameters, and the feed rate and spindle speed dynamic welding parameters at 
$R_{D W P}=0.5$, and compared to the as received $\mathrm{Al} 1050$ hardness. The values of the hardness results showed that the static welding parameter sample had a greater hardness value compared to dynamic welding parameters for the FR and SS samples. Thus, the static welding parameter sample was harder (less tough) than the dynamic welding parameter $F R$ and SS samples [32]. The reduction in the hardness of the dynamic welding parameters $S S$ and $F R$ was an indication of the enhancement in the toughness of the welds. This can be seen from Figure 15, which presents the comparison of the stress-strain curves of the welds produced by using SOP, $F R$ as DWP, and $S S$ as DWP. It can be seen that significantly higher areas are occupied by the stress-strain curves when $S S$ and FR are used as DWP ( $18.84 \%$ and $11.75 \%$, respectively) as compared to the stress-strain curve for SOP. This shows that the modulus of toughness is significantly higher in the cases when $S S$ and $F R$ are used as DWP. Furthermore, it is worth mentioning that the ultimate tensile strength (UTS) of the weld in the case when $S S$ is used as DWP ( $\sim 55 \mathrm{MPa})$ is very close to the UTS of the unprocessed $\mathrm{Al} 1050$ material $[49,50]$. This shows that a considerable weld's strength is achieved.

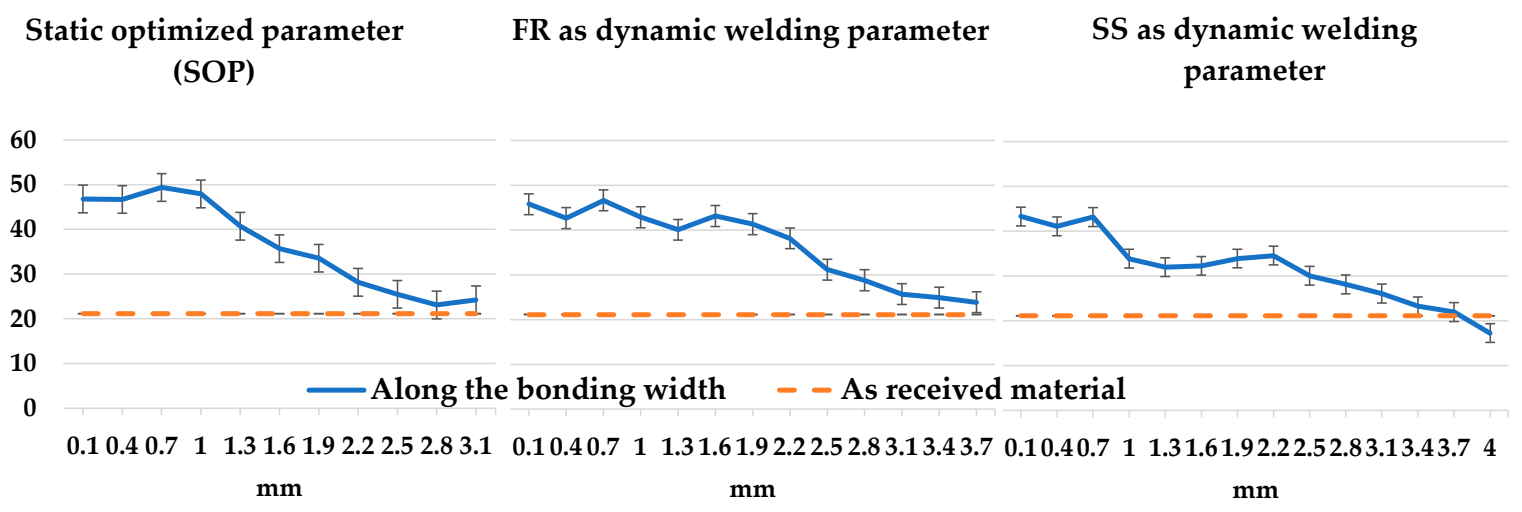

Figure 13. Microhardness results along the bonding width direction. The error bars show the maximum and the minimum value of the measurements.

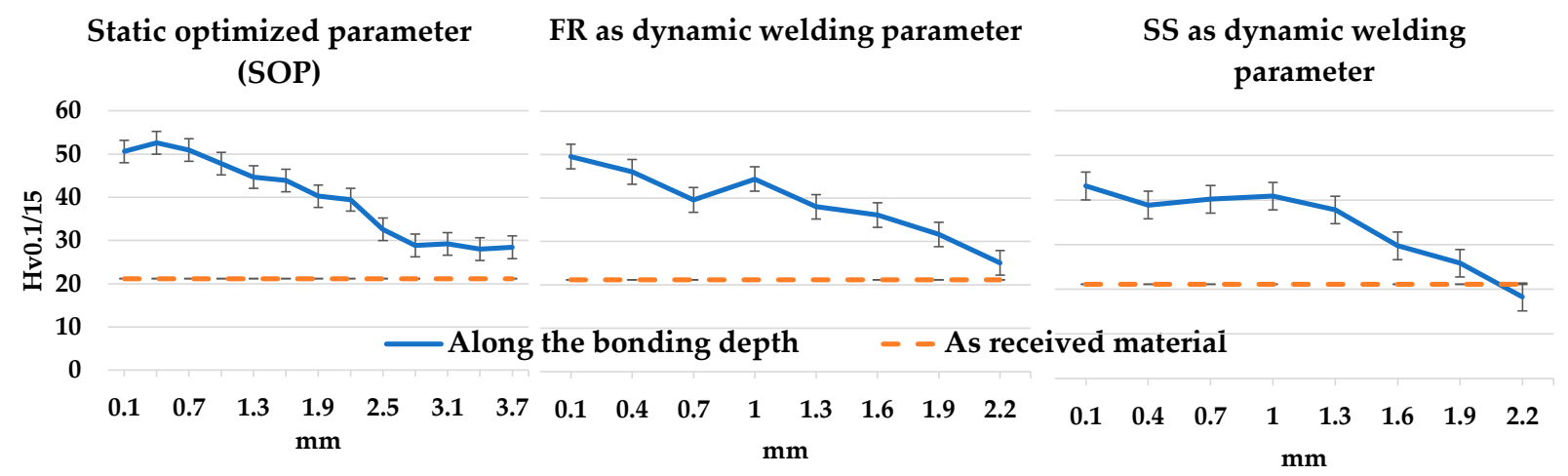

Figure 14. Microhardness results along the bonding depth direction. The error bars show the maximum and the minimum value of the measurements. 


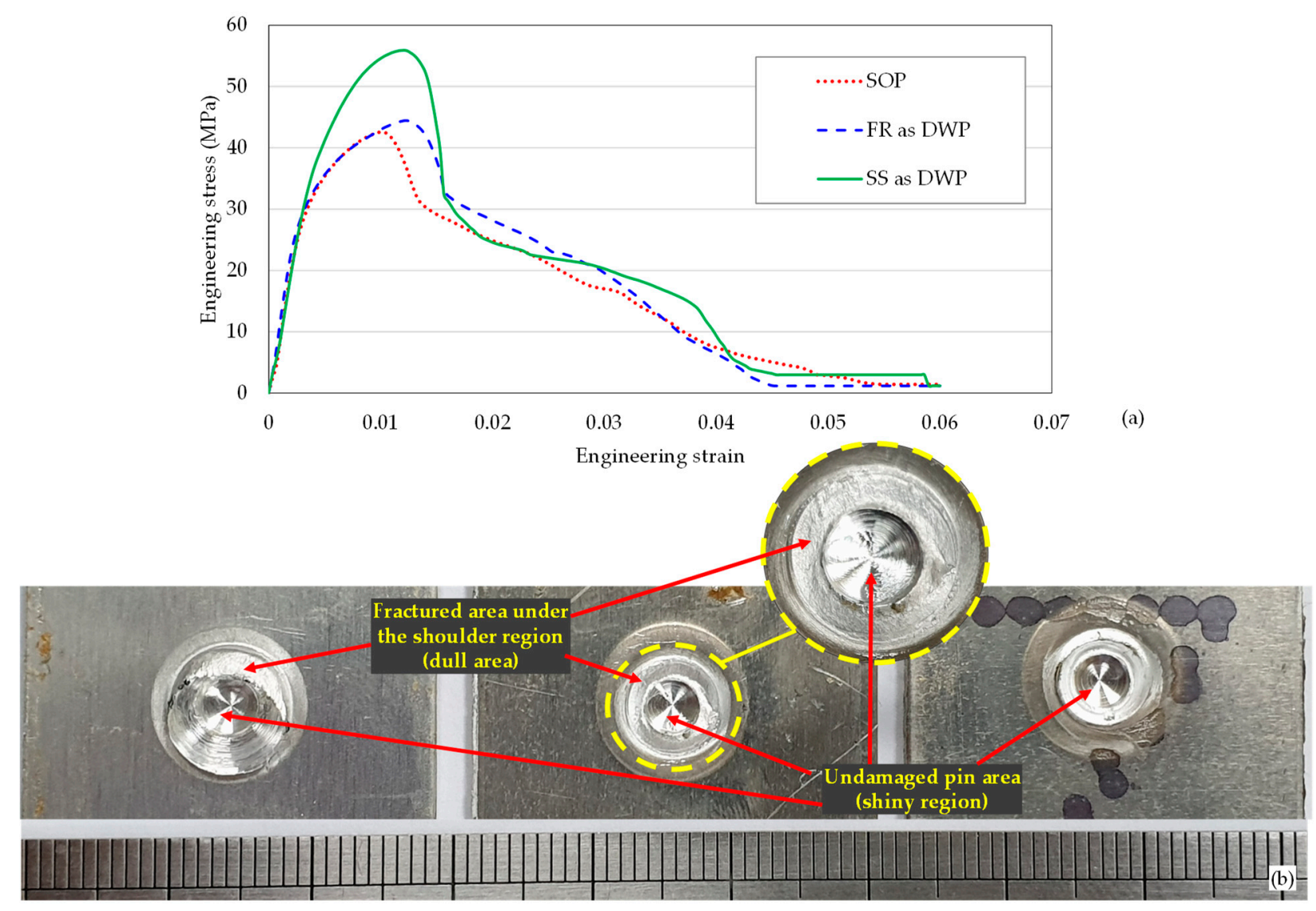

Figure 15. (a) Comparison of the stress-strain curves under different welding conditions. (b) Typical examples of the welds' fractured areas.

It should be noted that the engineering stress in the weld in Figure 15a was calculated by dividing the tensile loads (from the tensile test data) with the area of the weld that resists the fracture. The area of the weld $\left(65.94 \mathrm{~mm}^{2}\right)$ was calculated by using the Equation (2). The area of the pin was subtracted from the tool's cross-sectional area in Equation (2) based on the observations that even after the fracture of the welds, the pin areas were found to be undamaged, as shown in Figure 15b. Figure 15b shows typical examples of the fractured specimens of the weld. The fractured areas appear dull while the undamaged regions remain shining. In all the cases, the damage/fracture (dull area) always appear in the shoulder regions, whereas the pin regions remain shiny. Furthermore, it should be noted that the area of the weld could be calculated more accurately by considering the cross-sectional area based on the bonding width However, this approach was not used because the bonding width (as labelled in Figure 12b) can only be measured after cutting the weld from the middle. To avoid this, and to be consistent in calculating the engineering stress in all the welds, Equation (2) was used to calculate the area of the welds.

$$
\begin{gathered}
\text { Area of the weld }=\text { Cross }_{\text {sectional }} \text { area of the tool }- \text { Area of the tool pin } \\
\text { Area of the weld }=\pi 10^{2}-\pi 2^{2}=65.94 \mathrm{~mm}^{2}
\end{gathered}
$$

In Figure 16a, the bonding width is greater in the case when the $S S$ is employed as a dynamic welding parameter (DWP) compared to when feed rate is used as DWP, or when the static welding parameters are used. The bonding width for the spindle speed as a DWP was found to be $4.2 \mathrm{~mm}$ compared to 3.8 and $3.2 \mathrm{~mm}$ for other cases, as shown in Figure 16a. However, the highest hardness along the bonding depth in Figure 14 is recorded for that of the static welding parameters compared to the cases when SS and $F R$ are employed as dynamic welding parameters. The bonding depth was found to be 
$3.8 \mathrm{~mm}$ for static welding parameters as compared to 2.3 and $2.2 \mathrm{~mm}$, respectively for both $S S$ and $F R$ dynamic welding parameters, as shown in Figure 16a. It should be noted that the bonding widths in Figure 16a represent the average of the bonding widths measured on both sides of the pin.

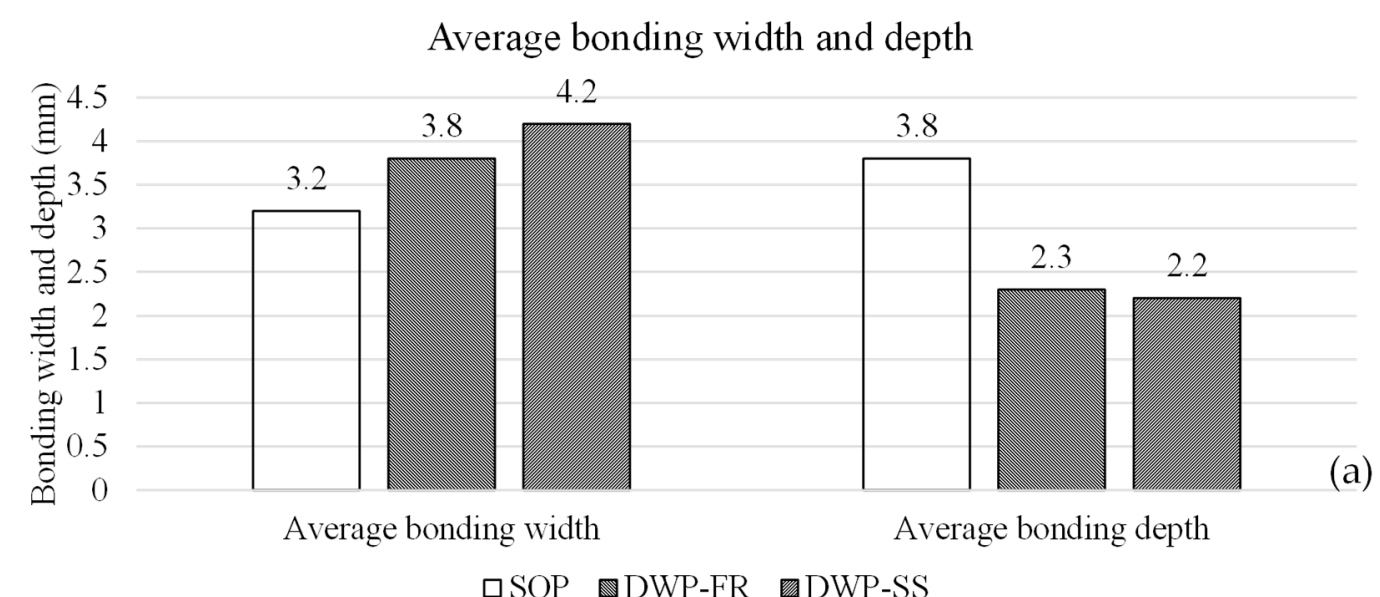

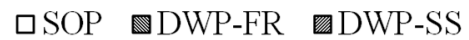

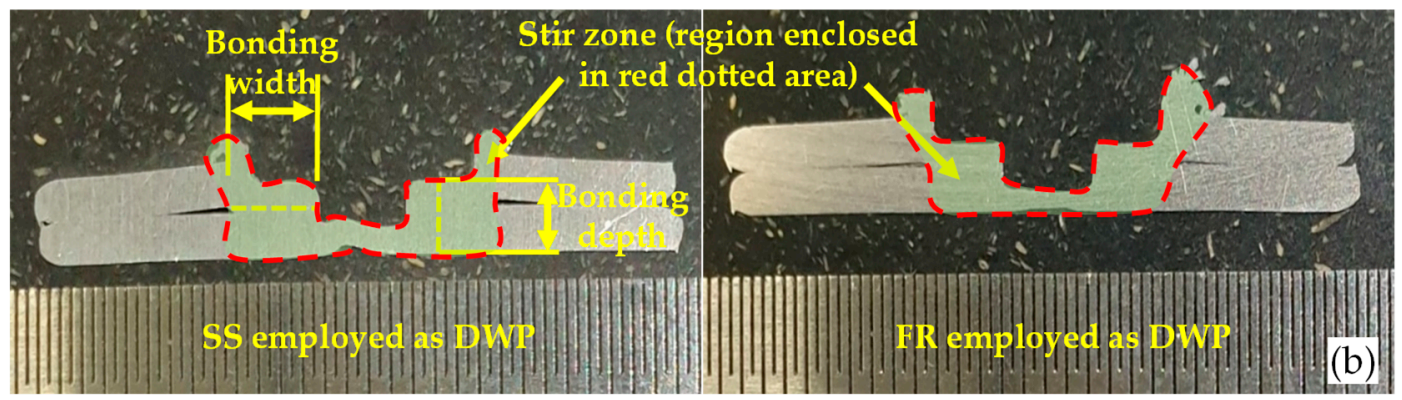

Figure 16. (a) Comparison of the average bonding width and depth below weld's shoulder. (b) Typical examples of the welds' cross-section showing the stir zone, and bonding width and depth.

The above results show that the width of the welds significantly increased when the dynamic welding parameters are employed, which in turn increases the area that resists the tensile load. It should be noted that the weld's strength is the function of the bonding width, while the gap region (see Figure 12a) has no effect on the weld's strength. This is because the actual material weld/joint develops only along the bonding width. Higher bonding width results in a high bonding area, which is reflected by the increase in the stress sustained by the welds produced with DWP, as shown in Figure 15. Higher bonding width in case of SS employed as DWP can be noticed in Figure $16 \mathrm{~b}$ as compared to when FR is employed as DWP.

\section{Summary and Conclusions}

This study explores the weld strength enhancement by introducing an innovative method that employs dynamic welding parameters (DWP) during the FSSW process. In the innovated method, the welding parameters are varied during the welding stroke. The two welding parameters selected to be varied during the welding stroke in this study are spindle speed and feed rate with a stepwise variation function. The experimental results prove the following:

- $\quad$ The proposed DWP method provides an enhancement in the welds' strength compared to when static welding parameters are used.

- As compared to the static welding parameters approach, increases of $12 \%$ and $21 \%$ were noted in the welds' strength corresponding to $R_{D W P}$ of 0.5 and 0.25 , respectively, when the spindle speed is used as DWP. 
- $\quad$ For the $R_{D W P}$ value higher than 1 , the weld strength decreases for both $S S$ and FR employed as DWP, due to the increase in the friction and temperature at higher values of $S S$ and FR.

- Overall, the feed rate was not found to be very effective for enhancing the welds strength when it was employed as a dynamic welding parameter as compared to the spindle speed.

\section{Patents}

The work in this manuscript has been registered as a patent: US 10442029, on 15 October 2019.

Author Contributions: A.B. wrote the paper and completed the experimental design; A.M.A.-S. supervision and provided project funding; S.A. revised the manuscript and helped in results; L.H. writing-review and editing. All authors have read and agreed to the published version of the manuscript.

Funding: The authors extend their appreciation to the Deanship of Scientific Research at King Saud University for funding this work through the research group no. (RG-1439-56).

Data Availability Statement: The data that have been used to support the findings of this study are available from the author Ahmed Badwelan (abadwelan@ksu.edu.sa) upon request.

Acknowledgments: The authors extend their appreciation to the Deanship of Scientific Research at King Saud University for funding this work through research group no. (RG-1439-56). The authors also thank the Deanship of Scientific Research and RSSU at King Saud University for their technical support.

Conflicts of Interest: The authors declare no conflict of interest.

\section{References}

1. Mortimer, J. Jaguar “Roadmap" rethinks self-piercing technology. Ind. Robot Int. J. 2005, 32, 209-213. [CrossRef]

2. Hancock, R. Friction welding of aluminum cuts energy costs by $99 \%$. Weld. J. N. Y. 2004, 83, 40-43.

3. Shibayanagi, T.; Mizushima, K.; Yoshikawa, S.; Ikeuchi, K. Friction stir spot welding of pure aluminum sheet in view of high temperature deformation. Trans. Join. Weld. Res. Inst. 2011, 40, 1-5.

4. Pan, T.-Y. Friction Stir Spot Welding (FSSW)—A Literature Review; SAE Technical Paper; SAE International: Warrendale, PA, USA, 2007.

5. Bozkurt, Y.; Türker, A.; Soytemiz, G.; Salman, S. The Investigation and Comparison of Friction Stir Spot Welding and Electrical Resistance Spot Welding of AA2024 Aluminium Alloy Joints. In Proceedings of the ICENS 4th International Conference on Engineering and Natural Science, Kiev, Ukraine, 2-6 March 2018.

6. Yuan, W. Friction Stir Spot Welding of Aluminum Alloys; Missouri University of Science and Technology: Rolla, MI, USA, 2008.

7. Lacki, P.; Derlatka, A.; Galaczynski, T. Selection of Basic Position in Refill Friction Stir Spot Welding of 2024-T3 and D16utw Aluminum Alloy Sheets. Arch. Met. Mater. 2017, 62, 443-449. [CrossRef]

8. Gerlich, A.; Avramovic-Cingara, G.; North, T.H. Stir zone microstructure and strain rate during Al 7075-T6 friction stir spot welding. Met. Mater. Trans. A 2006, 37, 2773-2786. [CrossRef]

9. Iwashita, T. Method and Apparatus for Joining. Google Patents EP1149656A3, 22 October 2003.

10. Meilinger, Á.; Török, I. The importance of friction stir welding tool. Prod. Process. Syst. 2013, 6, 25-34.

11. Mishra, R.S.; Mahoney, M.W. The Materials Information Society. In Friction Stir Welding and Processing; ASM International: Almere, The Netherland, 2007.

12. Su, Z.M.; Qiu, Q.H.; Lin, P.C. Design of Friction Stir Spot Welding Tools by Using a Novel Thermal-Mechanical Approach. Materials 2016, 9, 677. [CrossRef]

13. Kim, J.R.; Ahn, E.Y.; Das, H.; Jeong, Y.H.; Hong, S.T.; Miles, M.; Lee, K.J. Effect of Tool Geometry and Process Parameters on Mechanical Properties of Friction Stir Spot Welded Dissimilar Aluminum Alloys. Int. J. Precis. Eng. Manuf. 2017, 18, 445-452. [CrossRef]

14. Li, Z.W.; Yue, Y.M.; Ji, S.D.; Peng, C.; Wang, L. Optimal design of thread geometry and its performance in friction stir spot welding. Mater. Des. 2016, 94, 368-376. [CrossRef]

15. Paidar, M.; Sadeghi, F.; Najafi, H.; Khodabandeh, A.R. Effect of Pin and Shoulder Geometry on Stir Zone and Mechanical Properties of Friction Stir Spot-Welded Aluminum Alloy 2024-T3 Sheets. J. Manuf. Sci. Eng. Theor. ASME 2015, 137. [CrossRef]

16. Abbass, M.K.; Hussein, S.K.; Khudhair, A.A. Optimization of Mechanical Properties of Friction Stir Spot Welded Joints for Dissimilar Aluminum Alloys (AA2024-T3 and AA 5754-H114). Arab. J. Sci. Eng. 2016, 41, 4563-4572. [CrossRef]

17. Chen, K.; Liu, X.; Ni, J. Effects of Process Parameters on Friction Stir Spot Welding of Aluminum Alloy to Advanced High-Strength Steel. J. Manuf. Sci. Eng. Theor. ASME 2017, 139, 081016. [CrossRef] 
18. Paidar, M.; Khodabandeh, A.; Najafi, H.; Rouh-Aghdam, A.S. Effects of the tool rotational speed and shoulder penetration depth on mechanical properties and failure modes of friction stir spot welds of aluminum 2024-T3 sheets. J. Mech. Sci. Technol. 2014, 28, 4893-4898. [CrossRef]

19. Patel, V.V.; Sejani, D.J.; Patel, N.J.; Vora, J.J.; Gadhvi, B.J.; Padodara, N.R.; Vamja, C.D. Effect of Tool Rotation Speed on Friction Stir Spot Welded AA5052-H32 and AA6082-T6 Dissimilar Aluminum Alloys. Met. Microstruct. 2016, 5, 142-148. [CrossRef]

20. Sekhar, S.R.; Chittaranjandas, V.; Govardhan, D.; Karthikeyan, R. Effect Of Tool Rotational Speed On Friction Stir Spot Welded Aa5052-H38 Aluminum Alloy. Mater. Today Proc. 2018, 5, 5536-5543. [CrossRef]

21. Pattanaik, A.K.; Pradhan, S.; Panda, S.N.; Bagal, D.K.; Pal, K.; Patnaik, D. Effect of Process Parameters on Friction Stir Spot Welding Using Grey Based Taguchi Methodology. Mater. Today Proc. 2018, 5, 12098-12102. [CrossRef]

22. Piccini, J.M.; Svoboda, H.G. Effect of the tool penetration depth in Friction Stir Spot Welding (FSSW) of dissimilar aluminum alloys. Procedia Mater. Sci. 2015, 8, 868-877. [CrossRef]

23. Rana, P.K.; Narayanan, R.G.; Kailas, S.V. Effect of rotational speed on friction stir spot welding of AA5052-H32/HDPE/AA5052H32 sandwich sheets. J. Mater. Process. Technol. 2018, 252, 511-523. [CrossRef]

24. Garg, A.; Bhattacharya, A. On lap shear strength of friction stir spot welded AA6061 alloy. J. Manuf. Process. 2017, 26, 203-215. [CrossRef]

25. Shahani, A.; Farrahi, A. Effect of stirring time on the mechanical behavior of friction stir spot weld of Al 6061-T6 lap-shear configuration. Proc. Inst. Mech. Eng. Part C J. Mech. 2019, 233, 3583-3591. [CrossRef]

26. Boucherit, A.; Avettand-Fenoel, M.N.; Taillard, R. Effect of a Zn interlayer on dissimilar FSSW of Al and Cu. Mater. Des. 2017, 124, 87-99. [CrossRef]

27. Bakavos, D.; Prangnell, P.B. Effect of reduced or zero pin length and anvil insulation on friction stir spot welding thin gauge 6111 automotive sheet. Sci. Technol. Weld. Join. 2009, 14, 443-456. [CrossRef]

28. Choi, D.H.; Ahn, B.W.; Lee, C.Y.; Yeon, Y.M.; Song, K.U.; Jung, S.B. Effect of Pin Shapes on Joint Characteristics of Friction Stir Spot Welded AA5J32 Sheet. Mater. Trans. 2010, 51, 1028-1032. [CrossRef]

29. Zhou, L.; Zhang, R.X.; Li, G.H.; Zhou, W.L.; Huang, Y.X.; Song, X.G. Effect of pin profile on microstructure and mechanical properties of friction stir spot welded Al-Cu dissimilar metals. J. Manuf. Process. 2018, 36, 1-9. [CrossRef]

30. Hirasawa, S.; Badarinarayan, H.; Okamoto, K.; Tomimura, T.; Kawanami, T. Analysis of effect of tool geometry on plastic flow during friction stir spot welding using particle method. J. Mater. Process. Technol. 2010, 210, 1455-1463. [CrossRef]

31. Tozaki, Y.; Uematsu, Y.; Tokaji, K. Effect of tool geometry on microstructure and static strength in friction stir spot welded aluminium alloys. Int. J. Mach. Tools Manuf. 2007, 47, 2230-2236. [CrossRef]

32. Ojo, O.O.; Taban, E.; Kaluc, E.; Sik, A. Cyclic lateral behavior of friction stir spot welds of AA2219 aluminum alloy: Impact of inherent flow defects. Kov. Mater. 2019, 57, 329-342. [CrossRef]

33. Minitab. What Are Individual Desirability and Composite Desirability? Available online: https://support.minitab.com/en-us/ minitab/18/help-and-how-to/modeling-statistics/using-fitted-models/supporting-topics/response-optimization/what-areindividual-desirability-and-composite-desirability / (accessed on 27 January 2021).

34. Safdarian, R.J.J.o.S.M. The Effects of Forming Parameters on the Single Point Incremental Forming of 1050 Aluminum Alloy Sheet. J. Solid Mech. 2019, 11, 825-841.

35. Khan, F.; Qayyum, F.; Asghar, W.; Azeem, M.; Anjum, Z.; Nasir, A.; Shah, M. Effect of various surface preparation techniques on the delamination properties of vacuum infused Carbon fiber reinforced aluminum laminates (CARALL): Experimentation and numerical simulation. J. Mech. Sci. Technol. 2017, 31, 5265-5272. [CrossRef]

36. Sun, X.; Dong, P. Analysis of aluminum resistance spot welding processes using coupled finite element procedures. Weld. J. 2000, 79, 215s-221s.

37. Karthikeyan, R.; Balasubramanian, V. Predictions of the optimized friction stir spot welding process parameters for joining AA2024 aluminum alloy using RSM. Int. J. Adv. Manuf. Technol. 2010, 51, 173-183. [CrossRef]

38. Mekri, H.; Bouchouicha, B.; Miloudi, A.; Christophe, H.; Imad, A. Influence of the coupling between the mechanical characteristics and the welding conditions by the FSSW process: Case of the bi-material aluminum-steel. Frat. Integrità Strutt. 2018, 46, 62-72. [CrossRef]

39. Cepeda-Jimenez, C.M.; Hidalgo, P.; Pozuelo, M.; Ruano, O.A.; Carreno, F. Influence of Constituent Materials on the Impact Toughness and Fracture Mechanisms of Hot-Roll-Bonded Aluminum Multilayer Laminates. Met. Mater. Trans. A 2010, 41, 61-72. [CrossRef]

40. Bilici, M.K.; Yukler, A.I.; Kurtulmus, M. The optimization of welding parameters for friction stir spot welding of high density polyethylene sheets. Mater. Des. 2011, 32, 4074-4079. [CrossRef]

41. Dashatan, S.H.; Azdast, T.; Ahmadi, S.R.; Bagheri, A. Friction stir spot welding of dissimilar polymethyl methacrylate and acrylonitrile butadiene styrene sheets. Mater. Des. 2013, 45, 135-141. [CrossRef]

42. Bilici, M.K. Application of Taguchi approach to optimize friction stir spot welding parameters of polypropylene. Mater. Des. 2012, 35, 113-119. [CrossRef]

43. Abedini, O.; Ranjbarnodeh, E.; Marashi, P. Effect of tool geometry and welding parameters on the microstructure and static strength of the friction-stir spot-welded DP780 dual-phase steel sheets. Mater. Technol. 2017, 51, 687-694.

44. Farmanbar, N.; Mousavizade, S.M.; Ezatpour, H.R. Achieving special mechanical properties with considering dwell time of AA5052 sheets welded by a simple novel friction stir spot welding. Mar. Struct. 2019, 65, 197-214. [CrossRef] 
45. Paidar, M.; Ojo, O.O.; Moghanian, A.; Pabandi, H.K.; Elsa, M. Pre-threaded hole friction stir spot welding of AA2219/PP-C30S sheets. J. Mater. Process. Tech. 2019, 273, 116272. [CrossRef]

46. Buffa, G.; Fanelli, P.; Fratini, L.; Vivio, F. Influence of joint geometry on micro and macro mechanical properties of friction stir spot welded joints. Procedia Eng. 2014, 81, 2086-2091. [CrossRef]

47. Malik, V.; Sanjeev, N.K.; Hebbar, H.S.; Kailas, S.V. Time Efficient Simulations of Plunge and Dwell Phase of FSW and its Significance in FSSW. Procedia Mater. Sci. 2014, 5, 630-639. [CrossRef]

48. Pathak, N.; Bandyopadhyay, K.; Sarangi, M.; Panda, S.K. Microstructure and Mechanical Performance of Friction Stir Spot-Welded Aluminum-5754 Sheets. J. Mater. Eng. Perform. 2013, 22, 131-144. [CrossRef]

49. Pita, M.; Mashinini, P.M.; Tartibu, L.K. Enhancing of aluminum alloy 1050-H4 tensile strength by accumulative roll bonding process. In Proceedings of the 2020 IEEE 11th International Conference on Mechanical and Intelligent Manufacturing Technologies (ICMIMT), Cape Town, South Africa, 20-22 January 2020; pp. 31-35.

50. Bazarnik, P.; Bartkowska, A.; Romelczyk-Baishya, B.; Adamczyk-Cieślak, B.; Dai, J.; Huang, Y.; Lewandowska, M.; Langdon, T.G. Superior strength of tri-layered $\mathrm{Al}-\mathrm{Cu}-\mathrm{Al}$ nano-composites processed by high-pressure torsion. J. Alloys Compd. 2020, 846, 156380. [CrossRef] 